\title{
Analysis of Foramina of the Middle Cranial Fossa with Special Emphasis on Morphology and Morphometry of Foramen Ovale- An Observational Study
}

\section{ABSTRACT}

Introduction: Foramen Ovale (FO) is an important aperture present in the middle cranial fossa which transmits delicate neurovascular structures, especially the mandibular nerve. Morphological and morphometrical variations of this foramen are seen in literature and this knowledge is important as it is used for cannulation in rhizotomy for trigeminal neuralgia.

Aim: To analyse the foramina of the middle cranial fossa by emphasising on morphometry and morphology of FO as mandibular nerve passes through it.

Materials and Methods: This observational study was conducted in the Department of Anatomy, Vydehi Institute of Medical Sciences and Research,Banglore, Karnataka,India from January 2020 to June 2020. Fifty-one fully ossified adult skulls were utilised for this observational study. Antero-Posterior (AP) diameter, transverse diameter, area, and different shapes of the FO, distance between FO and other foramina, presence of foramen of Vesalius and accessory bony structures were studied. Independent sample t-test was done to compare the mean values of all the diameters.
Results: The AP and transverse diameter of FO on the right and left side was found to be almost symmetrical. AP diameter on the right and left side was found to be $6.79 \pm 1.4 \mathrm{~mm}$ and $6.78 \pm 1.3 \mathrm{~mm}$, respectively and transverse diameter was $3.58 \pm 0.90 \mathrm{~mm}$ on the right and $3.45 \pm 0.99$ on left side. Distance between FO and Foramen Spinosum (FS), foramen lacerum and Meckel's cave were similar on both the sides. The distance between FO and rotundum was greater on the right side i.e., $11.09 \pm 1.9 \mathrm{~mm}$ than left side which showed a diameter of $10.68 \pm 1.6 \mathrm{~mm}$. The different shapes of the FO observed were oval, almond, D-shaped, elongated, round, slit and irregular. Oval shape (22 skulls on the left side and 27 skulls on the right) was the most common type. Foramen of Vesalius was observed in four skulls and accessory bony structures like bony septum, plate and spurs were also seen in the current study.

Conclusion: The knowledge regarding the shape and distance between the FO and various foramina might benefit the neurosurgeons and radiologists during surgical procedures.

\section{INTRODUCTION}

The greater wing of sphenoid in the middle cranial fossa has numerous foramina that transmit vital structures. Foramen Ovale $(F O)$ is a connecting aperture between the middle cranial fossa and the infratemporal fossa which transmits the mandibular nerve, accessory meningeal artery, lesser petrosal nerve and an emissary vein. Middle cranial fossa in addition consists of Foramen Spinosum (FS), foramen lacerum (FL) and Foramen Rotundum (FR). Occasionally, two variant foramina named Foramen of Vesalius and Canaliculus innominatus are present, the former is present between $\mathrm{FO}$ and FR and the latter between FO and FS [1].

Foramen Ovale (FO) lies antero-medial to FS, lateral to FL and posterolateral to FR [2]. FO can be of different shapes and sometimes, it comprises of accessory bony structures like spurs, tubercles and spines which is associated with its development [3]. Sphenoid bone develops by forming presphenoid and postsphenoid centres. Presphenoid centres includes the basi sphenoid and orbitosphenoid which forms the body and lesser wings of sphenoid respectively and postsphenoid centre includes the alisphenoid which forms the greater wing and pterygoid process of sphenoid bone. During $7^{\text {th }}$ month of intrauterine life, the mandibular nerve gets enclosed in the unossified cartilage of greater wing of sphenoid and thus the FO is formed, during which it appears as a perfect ring shaped foramen [4,5].

Frequent variations of the $\mathrm{FO}$ include different shapes and changes in dimensions of $\mathrm{FO}$ and these differ between various ethnic groups
[6]. Hence, the morphometry of FO is significant as it is used as an entry point to ablate the mandibular nerve in a procedure termed as percutaneous stereotactic rhizotomy for relieving the pain in trigeminal neuralgia [7]. Additionally, the auriculotemporal, inferior alveolar, lingual, and buccal branches of mandibular nerve are anaesthetised by rhizotomy [8]. The trigeminal (Gasserian) ganglion in the Meckel's cave is accessed through the FO for surgical procedures [6].

The knowledge regarding the precise shapes and diameter of FO and distance between FO and various foramina might benefit the neurosurgeons and radiologists for management of surgeries. Hence, the aim of this study was to assess the morphometric values and morphology of the FO.

\section{MATERIALS AND METHODS}

This observational study was conducted in the Department of Anatomy, Vydehi Institute of Medical Sciences and Research Centre, Bangalore, Karnataka, India, from January 2020 to June 2020. Fiftyone fully ossified adult skulls of unknown sex and age were included in the study and those with obvious deformities were excluded. Ethical clearance was obtained from the Institutional Ethics Committee (VIEC/2021/APP/001). Total 102 sides in each skull were examined and the following parameters [Table/Fig-1] were taken into consideration:

AP diameter (Length) of the FO on the right and left side of each skull; Transverse diameter (Width) of the FO on the right and left side of each skull; Area was calculated by formula- pxAP diameter

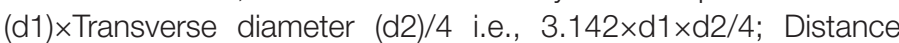






between FO and FS, FL, FR and Meckel's cave; Different shapes of $\mathrm{FO}$; Accessory bony structures in the FO;

Digital vernier callipers were used for all the morphometric measurements.

\section{STATISTICAL ANALYSIS}

The data was analysed using the Statistical Package for the Social Sciences (SPSS) for Windows version 19.0. Qualitative data was represented in the form of frequencies and percentage and quantitative data in the form of mean \pm Standard deviation. Independent sample t-test was done to compare the mean values of anteroposterior diameter, transverse diameter, area of FO, distance between FO and other foramina between right and left side. $\mathrm{p}<0.05$ was considered as statistically significant.

\section{RESULTS}

The present study showed a mean AP diameter of $6.79 \pm 1.4 \mathrm{~mm}$ on right side and $6.78 \pm 1.3 \mathrm{~mm}$ on the left. The mean transverse diameter on the right side and left side was $3.58 \pm 0.90 \mathrm{~mm}$ and $3.45 \pm 0.99 \mathrm{~mm}$, respectively. Area of FO was calculated and found as $19.68 \pm 8.84$ for right side and $18.90 \pm 8.64$ for left side [Table/Fig-2] . The observed mean values on both sides were not statistically significant ( $p>0.05$ ) which implies that morphometric difference is observed on right and left side of the skull.

\begin{tabular}{|l|c|c|c|c|c|c|}
\hline \multirow{2}{*}{$\begin{array}{l}\text { Foramen } \\
\text { ovale }\end{array}$} & \multicolumn{2}{|c|}{$\begin{array}{c}\text { AP diameter } \\
\text { (Length) in mm }\end{array}$} & \multicolumn{2}{c|}{$\begin{array}{c}\text { Transverse } \\
\text { diameter (Width) } \\
\text { in mm }\end{array}$} & \multicolumn{2}{|c|}{ Area in m $^{2}$} \\
\cline { 2 - 8 } & Right & Left & Right & Left & Right & Left \\
\hline \multirow{2}{*}{ Mean \pm SD } & $6.79 \pm$ & $6.78 \pm$ & $3.58 \pm$ & $3.45 \pm$ & $19.68 \pm$ & $18.90 \pm$ \\
& 1.4 & 1.3 & 0.90 & 0.99 & 8.84 & 8.64 \\
\hline \multirow{2}{*}{ Range } & $4.02-$ & $4.68-$ & $2.31-$ & $1.65-$ & $8.63-$ & $7.38-$ \\
& 10.98 & 10.51 & 6.38 & 6.90 & 55.02 & 51.48 \\
\hline
\end{tabular}

[Table/Fig-2]: Showing the Anteroposterior diameter, Transverse diameter, and area of Foramen Ovale (FO) on the right and left side of the skull.

The mean distance between FO and FS was found to be $5.28 \pm 1.3 \mathrm{~mm}$ on the right and $5.11 \pm 1.3 \mathrm{~mm}$ on the left side in the current study. The distance between FO and FL was found to be $7.41 \pm 1.5 \mathrm{~mm}$ on the right side and $7.26 \pm 1.4 \mathrm{~mm}$ on the left side. The distance between FO and FR was found to be $11.09 \pm 1.9 \mathrm{~mm}$ on the right and $10.68 \pm 1.6 \mathrm{~mm}$ on the left side. The distance between $\mathrm{FO}$ and Meckel's cave be $9.31 \pm 1.6 \mathrm{~mm}$ and $9.35 \pm 1.2 \mathrm{~mm}$ on the right and left side, respectively [Table/Fig-3]. The observed mean values on both sides were not statistically significant ( $p>0.05$ ).

The shapes of FO were categorised into various types and the most common shape was found to be oval and the least common shape was irregular. Detailed description of all the shapes observed is shown in the form of frequencies and percentages in [Table/Fig-4]. Among the accessory bony structures observed in the current study,

\begin{tabular}{|c|c|c|c|c|c|c|c|c|}
\hline \multirow[b]{2}{*}{ Parameters } & \multicolumn{2}{|c|}{$\begin{array}{l}\text { Distance } \\
\text { between } \\
\text { FO and FS } \\
\text { (in } \mathrm{mm} \text { ) }\end{array}$} & \multicolumn{2}{|c|}{$\begin{array}{c}\text { Distance } \\
\text { between } \\
\text { FO and FL } \\
\text { (in } \mathrm{mm} \text { ) }\end{array}$} & \multicolumn{2}{|c|}{$\begin{array}{c}\text { Distance } \\
\text { between FO } \\
\text { and FR (in } \mathrm{mm} \text { ) }\end{array}$} & \multicolumn{2}{|c|}{$\begin{array}{c}\text { Distance } \\
\text { between FO } \\
\text { and Meckel's } \\
\text { cave (in } \mathrm{mm} \text { ) }\end{array}$} \\
\hline & Right & Left & Right & Left & Right & Left & Right & Left \\
\hline Mean \pm SD & $\begin{array}{c}5.28 \pm \\
1.3\end{array}$ & $\begin{array}{c}5.11 \pm \\
1.3\end{array}$ & $\begin{array}{c}7.41 \pm \\
1.5\end{array}$ & $\begin{array}{c}7.26 \pm \\
1.4\end{array}$ & $\begin{array}{c}11.09 \pm \\
1.9\end{array}$ & $\begin{array}{c}10.68 \pm \\
1.6\end{array}$ & $\begin{array}{c}9.31 \pm \\
1.6\end{array}$ & $\begin{array}{c}9.35 \pm \\
1.2\end{array}$ \\
\hline Range & $\begin{array}{l}3.06- \\
8.40\end{array}$ & $\begin{array}{c}2.36- \\
9.35\end{array}$ & $\begin{array}{l}4.43- \\
12.45\end{array}$ & $\begin{array}{l}4.43- \\
10.44\end{array}$ & $\begin{array}{l}6.80- \\
15.26\end{array}$ & $\begin{array}{l}2.36- \\
9.35\end{array}$ & $\begin{array}{l}5.62- \\
13.27\end{array}$ & \\
\hline
\end{tabular}

[Table/Fig-3]: foramina.

bony septum was seen unilaterally on the left side in 1 skull (1.9\%), bony spur/spine was observed on the right side in 3 skulls $(5.8 \%)$ and on the left side in 2 skulls (3.9\%). One skull (1.9\%) in the present study exhibited bony plate on the right side [Table/Fig-5].

\begin{tabular}{|l|c|c|}
\hline $\begin{array}{l}\text { Different types of } \\
\text { shapes of FO }\end{array}$ & $\begin{array}{c}\text { No. of skulls on right side } \\
\mathbf{n}(\%)\end{array}$ & $\begin{array}{c}\text { No. of skulls on left side } \\
\mathbf{n}(\%)\end{array}$ \\
\hline Oval & $22(43.1)$ & $27(52.9)$ \\
\hline Almond & $10(19.6)$ & $10(19.6)$ \\
\hline D-shaped & $6(11.8)$ & $5(9.8)$ \\
\hline Elongated & $5(9.8)$ & $4(7.8)$ \\
\hline Round & $4(7.8)$ & $1(2)$ \\
\hline Slit & $4(7.8)$ & $2(3.9)$ \\
\hline Irregular & 0 & $2(3.9)$ \\
\hline \multicolumn{2}{|c|}{ [Table/Fig-4]: Showing the different shapes of FO on right and left side of the skull. }
\end{tabular}

\begin{tabular}{|l|c|c|}
\hline $\begin{array}{l}\text { Accessory bony } \\
\text { structures }\end{array}$ & $\begin{array}{c}\text { Number of skulls on the } \\
\text { right side }\end{array}$ & $\begin{array}{c}\text { Number of skulls on the } \\
\text { left side }\end{array}$ \\
\hline Bony septum & 0 & $1(1.9 \%)$ \\
\hline Bony spur & $3(5.8 \%)$ & $2(3.9 \%)$ \\
\hline Bony plate & $1(1.9 \%)$ & $2(3.9 \%)$ \\
\hline [Table/Fig-5 ]: Showing the accessory bony structures present on right and left
\end{tabular}
side of the skulls.

\section{Foramen of Vesalius (FV)}

Among 51 skulls, FV was observed in 4 (7.8\%) skulls. It was seen on the right side in 3 skulls (2.9\%) and on the left side in 1 skull $(0.98 \%)$ i.e., it was found bilaterally in 1 skull and unilaterally in 2 skulls, both on the right side.

\section{DISCUSSION}

Measurements of the FO are important as they vary morphologically and morphometrically and sometimes show presence of bony outgrowths like spurs, plates, spines etc. It is present in a transition zone between the intracranial and extracranial structures which makes it a crucial zone for diagnostic and surgical approach $[9,10]$. The knowledge of these variants is vital not just for rhizotomy, but also for cannulation in amygdalohippocampectomy and parasellar lesions biopsy [11].

In the present study, the mean AP diameter and mean transverse diameter of FO exhibited on the right and left side corresponds to a few studies which were also of Indian origin $[9,12]$. However, a higher mean length and width was also seen in studies by Somesh MS et al., [13] and Karthikeyan G et al., [14]. Kanyata D et al., opine that Kenyan skulls have a larger FO when compared to other populations and their study also showed greater diameters [6]. Another study by Bokhari $\mathrm{ZH}$ et al., which was done in skulls belonging to Lahore population, also showed higher length and width when compared to the present study [2]. In the current study, the area of FO was calculated on both the sides which was lower when compared to a study by Somesh MS et al., which was conducted on southern Indian ethnic skulls [13]. However, area calculated in a study by Bokhari $\mathrm{ZH}$ et al., showed similar results as the present study [2]. Hence, the results regarding the AP and transverse diameter and area in different populations are inconclusive [Table/Fig-6] [2,5,6,9,12,13]. 


\begin{tabular}{|l|c|c|c|c|c|c|}
\hline Authors & AP diameter (Right) & AP diameter (Left) & Transverse diameter (Right) & Transverse diameter (Left) & Area (Right) & Area (Left) \\
\hline Daimi SR et al. [9] (2011) & $6.60 \pm 1.06$ & $6.26 \pm 1.23$ & $3.70 \pm 0.81$ & $3.34 \pm 0.77$ & - & - \\
\hline Somesh MS et al. [13](2011) & $7.64 \pm 1.194$ & $7.562 \pm 1.123$ & $5.128 \pm 0.827$ & $5.244 \pm 0.950$ & $30.8 \pm 7.54$ & $31.31 \pm 8.26$ \\
\hline Patil J et al. [5] (2013) & $7.0 \pm 1.08$ & $6.8 \pm 1.40$ & $5.0 \pm 0.42$ & $4.70 \pm 0.91$ & - & - \\
\hline Kanyata D et al. [6] (2015) & $7.69 \pm 1.31$ & $7.68 \pm 1.23$ & $4.24 \pm 0.64$ & $4.28 \pm 0.74$ & - & - \\
\hline Bokhari ZH et al. [2] (2017) & $7.04 \pm 1.08$ & $7.18 \pm 1.14$ & $5.15 \pm 0.92$ & $3.99 \pm 0.86$ & $21.7 \pm 4.94$ & $21.08 \pm 4.69$ \\
\hline Shankar G et al. [12] (2019) & $6.62 \pm 1.11$ & $6.72 \pm 1.08$ & $3.78 \pm 0.89$ & $3.89 \pm 0.73$ & - & - \\
\hline Present Study (2020) & $6.79 \pm 1.4$ & $6.78 \pm 1.3$ & $3.58 \pm 0.90$ & $3.45 \pm 0.99$ & $19.68 \pm 8.84$ & $18.90 \pm 8.64$ \\
\hline
\end{tabular}

The mean distance between FO and FS was found to be $5.28 \pm 1.3 \mathrm{~mm}$ on the right and $5.11 \pm 1.3 \mathrm{~mm}$ on the left side in the current study, which differs from a study where the distance between FO and FS in males was $4.0 \mathrm{~mm}$ and $3.0 \mathrm{~mm}$ on the right and left side, respectively; and in females it was $3.6 \mathrm{~mm}$ (right side) and $3.2 \mathrm{~mm}$ (left side) [10]. Dogan NU et al., found the mean diameter to be $2.88 \pm 1.74$ and $2.76 \pm 1.22$ on the right and left side, respectively [15]. This study was done on fresh cadaveric skulls and the values differed greatly from the present study. However, the mean diameter was greater on the right than left side which is similar to the present study. A study by Khairnar KB and Bhusari PA also showed greater diameter on right side in both males and females [10]. Further studies based on the distance between FO and FS are required for the same as both these foramina lie close to each other and both open into the infra temporal fossa. Also, the knowledge of doubled FS, confluence of FO and FS and presence/ absence of canaliculus innominatus is also important for surgical procedures [10], even though these variations were absent in the present study.

Foramen lacerum is an aperture formed from incomplete convergence of the sphenoid, temporal and occipital bone and accommodates the internal carotid artery in its superior part. Exposure of this foramen is a requirement in resection of skull base lesions, especially chondrosarcomas as they are present usually around the FL [16]. The distance between FO and FL was found to be $7.41 \pm 1.5 \mathrm{~mm}$ on the right side and $7.26 \pm 1.4 \mathrm{~mm}$ on the left side in the present study and to the best of our knowledge this was not dealt with the earlier studies.

The distance between FO and FR was found to be $11.09 \pm 1.9 \mathrm{~mm}$ on the right and $10.68 \pm 1.6 \mathrm{~mm}$ on the left side. Usually, the FR opens into the pterygopalatine fossa and the maxillary nerve passes through it. However, a tiny opening in the floor of the FR that leads to the infratemporal fossa can be present sometimes and this was seen in 5 out of 50 skulls [17] and 16 out of 98 skulls in another study where this foramen was named as the inferior rotunda canal, and it is believed to transmit emissary veins [1].

The distance between FO and Meckel's cave was measured to provide an insight for performing surgical procedures through FO to reach the trigeminal/gasserian ganglion housed in the Meckel's cave [6]. The distance between these two landmarks was found to be $9.31 \pm 1.6 \mathrm{~mm}$ and $9.35 \pm 1.2 \mathrm{~mm}$ on the right and left side, respectively in the present study.

Foramen of Vesalius or sphenoid emissary foramen was found totally in four skulls $(7.8 \%)$ out of 51 i.e., $3(2.9 \%)$ on the right side and in $1(0.98 \%)$ on the left side. The current readings were lesser when compared to another study, where it was seen in $7 \%$ on right and $3 \%$ on left side [12]. FV was seen in 10 skulls out of 64 in a study by Karthikeyan $\mathrm{G}$ et al., [14]. In a study where 377 skulls were examined for FV in both middle cranial fossa and norma basalis, it was observed in 10.9\% (82 of 754 sides) and 25.9\% (195 of 754 sides) respectively. They also observed it to be more on the left side than right and more in males than females [18]. Another study used high resolution CT to examine the middle cranial fossa of 123 skulls and found FV unilaterally in 38 skulls (30.8\%) and bilaterally in 60 skulls (48.7\%) which is higher when compared to the other studies [1]. The data on FV based on the previous literature and the present study shows inconsistency. FV, if present lies close to FO and sometimes, both these foramina can confluence. Hence, further studies are necessary as during Rhizotomy, needle targeting the trigeminal ganglion may be misplaced and can lead to intra cranial bleeding as FV connects the pterygoid venous plexus to cavernous sinus and an emissary vein that drains the cavernous sinus passes through it [18].

It is of utmost importance to study the different shapes of FO and accessory bony structures as mandibular nerve can get compressed in this opening which can ultimately lead to trigeminal neuralgia. The morphology of $\mathrm{FO}$ is also necessary for neurosurgical procedures such as biopsy of cavernous sinus tumours and it serves as a route to administer anaesthesia [2,5]. The categorisation of the different shapes of FO observed in the present study were consistent with previous reports in which oval was the most common shape and the second most being almond $[3,4,10,13]$. However, in a study by Daimi SR et al., D-shape was the most common type (46.16\%) followed by oval (29.87\%) [9]. In another study, on 30 skulls, round shape was seen in 3 on the right side and 1 on the left side [3], which is similar to the present study (4 round shaped FO on the right and 1 on the left). However, 8 skulls exhibited round $\mathrm{FO}$ on the right and 10 skulls on the left which was higher when compared to the present study [13]. Slit shape was seen in lower percentage in the previous studies too (1.8\%, 1.04\%, 2\%) [4,9,19]. Irregular shaped FO was observed in one skull on the left side and none on the right side in a study by Bokhari $\mathrm{ZH}$ et al., which was similar to the present study and in a study by Somesh MS et al., it was observed in 2 skulls on the right side and 4 on the left side $[2,13]$.

The presence of an osseous lamina dividing the foramen into two halves which is nothing, but the bony septum was observed in 1 skull on the left side and none on the right side in as study by Bokhari ZH which is same as the present study which also showed septation on the left side in one skull [2]. Another study also mentions the presence of a bony septation in 1 skull out of 64 skulls on the right side [14]. Bony spine/spur was seen in 3 skulls on the right side and 2 skulls on the left side in one study [2] and 3 skulls on the right and 5 on the left in another [3] which was similar to our study. Bony plate was seen in 2 skulls on both the sides in a study by Bokhari $\mathrm{ZH}$ which was consistent with present study [2].

\section{Limitation(s)}

The limitation of the present study was the limited sample size (51 skulls) as the sampling population was limited to skulls in the department of Anatomy, VIMS and RC. Therefore, more studies are required with a larger sample size.

\section{CONCLUSION(S)}

Anteroposterior and transverse diameter of $\mathrm{FO}$ on the right and left side was found to be almost symmetrical. Distance between FO and FS, FL and Meckel's cave were similar on both the sides. The distance between FO and FR was greater on the right side. The different shapes of the FO observed were oval, almond, D shaped, 
elongated, round, slit and irregular with oval shape being the most common type. Foramen of Vesalius and accessory bony structures were also observed. This study aimed at providing an insight about foramina of the middle cranial fossa with emphasis on FO as it will be helpful for clinicians in conducting therapeutic procedures like rhizotomy for trigeminal neuralgia without any difficulties.

\section{REFERENCES}

[1] Ginsberg LE, Pruett SW, Chen MY, Elster AD. Skull-base foramina of the middle cranial fossa: Reassessment of normal variation with high-resolution CT. American Journal of Neuroradiology. 1994;15(2):283-91.

[2] Bokhari ZH, Munira M, Samee SM, Tafweez R. A Morphometric Study of FO in Dried Human Skulls. Pakistan Journal of Medical \& Health Sciences. 2017;11(4):1661-65.

[3] John DA. Anatomical Variations of FO. Journal of Pharmaceutical Sciences and Research. 2015;7(6):327.

[4] Yanagi S. Developmental studies on the foramen rotundum, foramen ovale and foramen spinosum of the human sphenoid bone. [Hokkaido igakuzasshi] The Hokkaido Journal of Medical Science. 1987;62(3):485-96.

[5] Patil J, Kumar N, Mohandas Rao KG, Swamy Ravindra S. The FO morphometry of sphenoid bone in South Indian population. Journal of clinical and diagnostic research: JCDR. 2013;7(12):2668.

[6] Kanyata D, Odula P, Nyamai LA, Nduati PK. Morphology and location of surface landmarks of FO in Kenyans. Int J Morphol. 2015;33(2):471-475.

[7] Taha JM, Tew JM, Buncher CR. A prospective 15-year follow up of 154 consecutive patients with trigeminal neuralgia treated by percutaneous stereotactic radiofrequency thermal rhizotomy. Journal of Neurosurgery. 1995;83(6):989-93.

[8] Ranganathan TS. A text book of Human Anatomy. S. Chand; 1987.
[9] Daimi SR, Siddiqui AU, Gill SS. Analysis of FO with special emphasis on pterygoalar bar and pterygoalar foramen. Folia Morphologica. 2011;70(3):149-53.

[10] Khairnar KB, Bhusari PA. An anatomical study on the foramen ovale and the foramen spinosum. Journal of Clinical and Diagnostic Research: JCDR. 2013;7(3):427.

[11] Zdilla MJ, Hatfield SA, McLean KA, Laslo JM, Cyrus LM, Lambert HW. Orientation of the FO: An anatomical study with neurosurgical considerations. The Journal of Craniofacial Surgery. 2016;27(1):234.

[12] Shankar G, Muthukumaravel N. A morphological and morphometric study of FO in dry skulls of Indian population. National Journal of Clinical Anatomy. 2019;8(1):38.

[13] Somesh MS, Sridevi HB, Prabhu LV, Swamy MS, Krishnamurthy A, Murlimanju BV, et al. A morphometric study of FO. Turkish Neurosurgery. 2011;21(3):378-83.

[14] Karthikeyan G, Sankaran PK, Gunapriya R, Yuvaraj M, Rohini A. Morphometric study of various foramina in the middle cranial fossa of the human skull. Indian Journal of Clinical Anatomy and Physiology. 2017;4(4):574-78.

[15] Dogan NU, Fazhogullari Z, Uysal II, Seker M, Karabulut AK. Anatomica examination of the foramens of the middle cranial fossa. Int $\mathrm{J}$ Morphol. 2014;32(1):43-48.

[16] Wang WH, Lieber S, Mathias RN, Sun X, Gardner PA, Snyderman CH, et al. The foramen lacerum: Surgical anatomy and relevance for endoscopic endonasal approaches. Journal of Neurosurgery. 2018;131(5):1571-82.

[17] Sondheimer FK. Basal foramina and canals, in Radiology of the Skull and Brain vol 1, edited by Newton TH, Potts DG, St. Louis, Mosby, 1971, 289-347.

[18] Chaisuksunt V, Kwathai L, Namonta K, Rungruang T, Apinhasmit W, Chompoopong S. Occurrence of the foramen of Vesalius and its morphometry relevant to clinical consideration. The Scientific World Journal. 2012;2012.

[19] Naqshi BF, Shah AB, Gupta S. Variations in foramen ovale and foramen spinosum in human skulls of north Indian population. International Journal of Contemporary Medical Research. 2017;4(11):2262-65.

\section{PARTICULARS OF CONTRIBUTORS:}

1. PhD Scholar, Department of Anatomy, Chettinad Academy of Research and Education, Chennai, Tamil Nadu, India.

2. PhD Scholar, Department of Anatomy, Vydehi Institute of Medical Sciences and Research Centre, Bangalore, Karnataka, India.

3. Assistant Professor, Department of Anatomy, Vydehi Institute of Medical Sciences and Research Centre, Bangalore, Karnataka, India.

\section{NAME, ADDRESS, E-MAIL ID OF THE CORRESPONDING AUTHOR:}

Dr. R Showri,

G 003, Shravanthi Paramount, Hulimavu, Bannerghatta Road,

Bangalore-560076, Karnataka, India.

E-mail: showri.123@gmail.com
PLAGIARISM CHECKING METHODS: [Jain Het al.]

- Plagiarism X-checker: May 28, 2021

- Manual Googling: Sep 02, 2021

- iThenticate Software: Sep 24, 2021 (15\%)

\section{AUTHOR DECLARATION:}

- Financial or Other Competing Interests: None

- Was Ethics Committee Approval obtained for this study? Yes

- Was informed consent obtained from the subjects involved in the study? No

- For any images presented appropriate consent has been obtained from the subjects. No

Date of Submission: May 11, 2021 Date of Peer Review: Jun 30, 2021 Date of Acceptance: Sep 14, 2021 Date of Publishing: Jan 01, 2022 